Acta Poetica $35 \cdot 2$

JULIO-DICIEMBRE

$2014(51-67)$

\title{
Vos que me empezaste y quiero que me acabes en la mitad de vos. La mística de la poesía de Juan Gelman
}

\author{
Bianca Pamela Ramírez Rivera
}

La mística es una experiencia que muy pocas personas consiguen tener, y aun para esas personas es difícil expresar lo que significó y continúa significando en su vida. Relatos de místicos antiguos y contemporáneos se encuentran dispersos por todo el mundo y no se atienen a una sola religión. Así pues, es posible encontrar relatos de experiencias místicas de practicantes de diversas religiones como el islamismo, el judaísmo o el catolicismo.

Juan Gelman, poeta, ensayista y periodista argentino, es una de las figuras más importantes de la literatura de América Latina contemporánea. Con sus textos periodísticos y poemas, pudo denunciar las injusticias de la política de su país; y además fue una personalidad que relató descarnadamente uno de los procesos más cruentos ocurridos en Argentina: la dictadura militar.

Gelman también se acercó al fenómeno de la experiencia mística. Ya fuese por un sentimiento de identificación (al sentirse extranjero) o por la búsqueda de 'lo místico' (aquello que lo trasciende como ser humano), Gelman es un autor latinoamericano cuya etapa de poesía mística es fundamental para comprender este fenómeno por medio de la literatura.

En este ensayo se propone explorar la veta de Juan Gelman como buscador de la experiencia mística y relator de ella. Se rastreará esto a partir del material de esta índole que el autor dejó plasmado en sus obras Citas y Comentarios, Com/posiciones y dibaxu, además de la revisión que él mismo hizo de los místicos de tradición judía.

PALABRAS CLAVE: Gelman, mística, experiencia, dibaxu, tradición judía.

The mystical experience is a phenomenon that just a few people experience, and even for those people, it's complicated to explain what it meant and what it still means in their lives. Stories of ancient and contemporary mystics are scat- 
tered around the world and do not belong to a single religion. Thus, it is possible to find mystical experiences stories of practitioners of several religions such as Islam, Judaism or Catholicism.

Juan Gelman, poet, essayist and journalist, is one of the most important figures of contemporary literature in Latin America. With his journalistic texts and poems, he could denounce the injustices of his country's politics; and was also a personality that starkly gave an account of one of the bloodiest processes occurring in Argentine: the military dictatorship.

Gelman also approached the phenomenon of mystical experience. Whether it was a sense of identification (feeling as a foreigner) or through the search of 'the mystical' (which transcends him as a human being), Gelman is a Latin American author whose phase of mystical poetry is central to understand this phenomenon through literature.

This essay aims to explore Juan Gelman's vein as a seeker and narrator of mystical experience. This will be traced from the material of this nature that the author left in his works, Citas y Comentarios, Com/posiciones and Dibaxu, as well as from his revision of the jewish tradition mystics.

KEYWORDS: Gelman, mystical, experience, dibaxu, Jewish tradition.

Fecha de recepción: 29 de agosto de 2013

Fecha de aceptación: 24 de enero de 2014 


\author{
Bianca Pamela Ramírez Rivera \\ Universidad Nacional Autónoma de México \\ Facultad de Estudios Superiores Acatlán
}

\title{
Vos que me empezaste y quiero que me acabes en la mitad de vos. La mística de la poesía de Juan Gelman
}

\begin{abstract}
A Juan Gelman, poeta porteño de la segunda mitad del siglo xx, resulta complejo apresarlo en un solo género literario. Aunado a esto, las múltiples evocaciones y formas poéticas de que se vale el autor, son suficientes para imposibilitar su encasillamiento en alguna determinada corriente literaria. Resulta casi imposible aprehender completamente los contenidos y significaciones que Gelman quiso plasmar en su obra.

Bien se puede valer del ritmo de los tangos argentinos, de las formas poéticas de los judíos sefaradíes y los clásicos castellanos, de las protestas callejeras, o de los lamentos por la cotidianeidad, configurando un vasto lenguaje y un nuevo discurso. Si bien los temas que abarca la obra de Gelman son diversos (ya sea de corte político, de protesta, contestatario, erótico, amoroso e inclusive religioso), una de las constantes que empapa a sus textos es la búsqueda mística: mediante el relato, descripción o narración de una experiencia terrenal, intenta alcanzar la unión de la experiencia personal con aquello que lo trasciende como ser humano.
\end{abstract}

La experiencia mística, acariciada por algunos e imprevista para otros, es un fenómeno que quienes lo han vivido han intentado ponerlo en palabras. Mediante ésta se entra en un estado donde "el individuo adquiere plena certeza de Dios y de su propia naturaleza divina" (García, 
"Yo tuve una cosa", 15), siendo a menudo sobrepasados por este fenómeno quienes consiguen experimentarlo. Se trata de un estado alterado de la conciencia distinto de otros, pues aunque "el místico reconoce que lo que le aconteció es difícil de comprender para quien no lo haya experimentado, está convencido de haberlo vivido" (15).

Tal como anotase en su momento José Ángel Leyva (profundo admirador del poeta e investigador de su obra), la obra de Gelman es una suerte de "mística fundada en la poesía" ("Yo poeta", 10). Es decir, la inclusión de todos los elementos antes expuestos, son la constatación de la búsqueda de 'lo místico' (como experiencia o ideal) por parte del autor, hecha con mayor vigor tras la crisis de identidad, de patria y de pensamiento que experimentó en el exilio.

Un componente más de su obra son los heterónimos. Los 'otros' de Gelman pueden adoptar múltiples formas, nacionalidades, voces y estar inmersos en las más variadas situaciones: ser un extranjero, ser un protestante, ser un doliente, ser un enamorado, ser un exiliado. "Los Otros de Gelman son aves de diversos y plurales vientos. Pájaros que pueblan poemas, sonidos que remontan ramas y árboles genealógicos de otras altitudes y tiempos diferentes" (Leyva, "Yo poeta", 8).

\section{Yo soy el único argentino de esa familia}

La historia familiar de Juan Gelman es tanto o más compleja que su obra poética. Su padre era obrero y participó en la Revolución rusa de 1905, motivo por el cual tuvo que salir del territorio europeo sin su familia y refugiarse en Argentina. Más tarde y con el triunfo de la Revolución de 1917, regresó a Europa, pero no pudo ingresar a la URss por la guerra civil que la azotaba. Desde Berlín supervisó la salida de su mujer y sus dos hijos de Moscú, pero la barca que los sacaría de ahí se volteó y tanto su mujer como uno de sus hijos murieron. Boris, el hijo sobreviviente, esperó a su padre en Rusia. Hasta 1922 su padre puede regresar a territorio ruso, donde conoce a la madre de Juan, con quien se casa y procrea a una hija. Con Boris a su lado, regresan a Argentina en 1928. Dos años más tarde, nació Juan. "Yo soy el único argentino de 
esa familia" (Leyva y Gelman, "Juan Gelman”, 2), se refiere a sí mismo el poeta, pues nació y pasó importante parte de su vida en Argentina.

Villa Crespo fue el barrio que lo vio crecer y conoció sus primeras inquietudes románticas, su amor por el tango y la conciencia de reconocerse como 'otro': "viví y crecí en un barrio con mucha tradición tanguera, mezclado, porque también había una buena parte de inmigrados judíos y árabes" (2).

En la Universidad de Buenos Aires se propuso estudiar Química, pero en 1948 la abandonó para dedicarse a la poesía, al periodismo y al activismo político. En 1954, formando parte de la revista Muchachos, se integra al grupo de poetas conocido como "El Pan Duro". Durante su adhesión a este grupo, publicó su primer libro, Violín y Otras Cuestiones (1956), a la par que publicaba artículos en diversos diarios y editoriales del Partido Comunista argentino.

En el periodo de 1956 a 1958 redacta El Juego en que Andamos (1959); "periodo en el que el poeta, por sus críticas hacia el Partido Comunista argentino, se aleja del proyecto 'El Pan Duro' y se acerca a la revista Nueva Expresión" (Pérez, "Introducción”, 20). En 1963 y durante la presidencia de José María Guido, es encarcelado junto con otros intelectuales argentinos por su pertenencia al Partido Comunista y sus críticas al gobierno argentino. Traigo una Voz Encarcelada sería editada en su cautiverio, obra que contiene poemas de protesta de Gelman y otros poetas encarcelados.

Cuando salió de prisión, se apartó del comunismo ortodoxo y formó parte de las filas del peronismo revolucionario, además de formar con José Luis Mangieri y Juan Carlos Pontantiero la editorial "La Rosa Blindada". También fue editor y articulista de los periódicos La Opinión y Noticias, además de redactor en la revista Crisis.

Durante la primer dictadura militar en Argentina (la autodenominada Revolución Argentina), formó parte de la guerrilla FAR (Fuerzas Armadas Revolucionarias), que posteriormente evolucionarían en el grupo Montoneros. En estos años publicó los libros Traducciones III. Los poemas de Sydney West (1969), Fábulas (1971) y Relaciones (1973), donde ya se percibe en Juan Gelman la búsqueda de otras voces y su encuentro con los 'otros' Juan. 
La época más complicada de la vida de Gelman arribaría desde 1975, cuando fue nombrado emisario internacional por Montoneros para denunciar la represión militar en Argentina, razón por la cual salió de su país en representación del movimiento. Aquí comenzaría el peregrinar de Gelman por diversos países, diversas lenguas y diversos mundos: Italia, España, Francia, Nicaragua, Estados Unidos, México.

El 24 de marzo de 1975 ocurrió el golpe de Estado contra la entonces mandataria Isabel Perón y la instauración del Proceso de Reorganización Nacional, régimen que persiguió a intelectuales y opositores, además de desaparecer a poco más de 30,000 personas (Calvo, "Una duda histórica", 1). "A partir de ese momento se desató en el país una feroz e indiscriminada persecución y muerte de ciudadanos" (Dómina, 303): se sistematizó la persecución y desaparición de los disidentes de izquierda y se encarceló a las autoridades depuestas corruptas o vinculadas a grupos armados.

El golpe más duro llegaría durante este régimen de terror: el 26 de agosto de 1976, "los militares fueron a buscar a Gelman a su casa, y como no estaba, se llevaron a su hijo y a su nuera embarazada" (EFE, "Juan Gelman: el dolor no es la fuente de inspiración", 1), desapareciendo a ambos familiares. Dos años después y aún en el extranjero, en 1978, se enteró de que su nuera había sido trasladada a Uruguay, donde se le permitió dar a luz. En este punto se intensifica su peregrinar, no sólo físico sino también espiritual: para huir de los represores, por encontrar a su hijo y nuera, además de saber qué fue de su "nieto"; escribió artículos periodísticos, trabajó como traductor para la UNESCO y buscó la intercesión de gobiernos extranjeros para denunciar la represión militar en Argentina.

Sus experiencias en el exilio y sus ansias por preguntar a qué iría a parar todo, se vertieron en Hechos y Relaciones (1980), texto en el que "el combate y el dolor de tantas muertes llevan a numerosas interrogaciones directas encadenadas, en las que se bucea en la amarga experiencia" (Pérez, "Introducción", 42). Este exilio impuesto y el dolor de la pérdida de su familia, lo llevan a acercarse con mayor ímpetu a la búsqueda mística y la relectura de los clásicos e, inclusive, los personajes bíblicos: "los leí de otra manera porque estaba en el destierro, sintiendo en ellos, como en mí, la presencia ausente de lo amado: Dios para ellos, 
para mí los compañeros caídos, mi hijo, los desaparecidos, mi país" (Leyva y Gelman, “Juan Gelman”, 9).

En 1983 asumió Raúl Alfonsín la presidencia argentina y con ello terminó la dictadura militar, proceso al cual se nombró Vuelta a la Democracia. No obstante, debido a que se perseguían a los miembros de Montoneros, Juan Gelman no pudo regresar a su país. Ello provocó las protestas de intelectuales argentinos y extranjeros, entre ellos Octavio Paz, Gabriel García Márquez, Juan Carlos Onetti y Mario Vargas Llosa. El crimen imputado a Montoneros proscribió en febrero de 1988, razón por la cual Gelman pudo volver a Argentina tras 13 años de exilio; sin embargo, debido a que poseía una postura política contraria al proyecto de Alfonsín, decidió salir del país y fijar su residencia en México.

E1 7 de enero de 1990 y en el marco de las investigaciones por esclarecer los asesinatos y desapariciones ocurridas durante la represión militar de 1975, fue encontrado el cuerpo de su hijo en el río San Fernando, dentro de un contenedor de grasa con cemento. Con este hallazgo, a Juan Gelman aún le restaba conocer el paradero de su "nieto".

En el año 2000 la incesante búsqueda del poeta daría frutos: su nieta Andrea fue encontrada con vida por el gobierno uruguayo de Jorge Batlle (Butazzoni, "El poeta Gelman", 1). La reunión de un Gelman de 70 años y una chica de 23 se llevó a cabo ese mismo año en Uruguay y con gran atracción mediática.

La primer década del siglo XXI continuó siendo de actividad literaria para Juan Gelman, pues escribió cuatro libros más: Valer la pena (2001), País que fue será (2004), Mundar (2007), De atrásalante en su porfia (2009). El emperrado corazón amora (2011). Aunado a esto, ha sido merecedor de varios reconocimientos en México y el mundo, entre ellos el de Literatura Latinoamericana y del Caribe 'Juan Rulfo' (2000), el Iberoamericano de Poesía 'Pablo Neruda' (2005), el Reina Sofía de Poesía Iberoamericana (2005), el Premio Cervantes (2007) y el Premio Leteo (2012).

Su última obra publicada fue Hoy (2013), antología poética con 287 poemas en prosa, la cual le tomó dos años en concluir. Mediante escritos cortos, parece "oponerse a esa concepción tan generalizada de que tarde o temprano se consuma el duelo, que siempre se encuentra 'consuelo' ante la muerte" (Friera, "Hay palabras ignoradas", 1). La muerte 
tocaría a la puerta del poeta a la edad de 83 años en su residencia de la ciudad de México, dejando un vacío enorme en la literatura de habla hispana y un legado de poesía de lucha y resistencia.

\section{Juan Gelman: el 'Otro'}

Si hubiese que preguntarse quién es realmente Juan Gelman, el sendero a seguir para encontrar la respuesta sería largo, tortuoso y con una empresa que promete no llevar a buen puerto. Gelman posee diversas voces, mismas que plasma desde 'sí mismo' o desde sus heterónimos (término con el que el autor no terminó de convencerse).

Los 'otros' de Juan Gelman son una suerte de recurso brechtiano de alejamiento de sí mismo. Es la exploración de otros senderos alternos a él, desde sí mismo, pero con el objetivo de no ser él. Los 'otros' de Gelman son tan particulares como la matriz misma: Sydney West, Yamanokuchi Ando, John Wendell, José Galván, Julio Grecco, entre otros tantos; un inglés, un japonés, un norteamericano, dos argentinos. El heterónimo es la forma de que se vale Gelman para verse a sí mismo a través de otros, pero también para pensar desde otros sin 'él': "inventé a John Wendell para extrañarme [...] mi poesía se estaba volviendo muy íntima" refirió Gelman a Mario Benedetti en una entrevista (Leyva y Gelman, "Juan Gelman”, 10).

La exploración a través de sus 'otros' también tiene el propósito de verse a sí mismo como extranjero. Esto sucede así en Traducciones (1969), donde dota a sus heterónimos de nacionalidades extrañas a él (inglesa, japonesa y norteamericana) y refiere que más que escribir a través de ellos, los traduce puesto que les confiere particularidades propias de él, pero reflejadas en escenarios completamente ajenos, como lo sería un vecindario de los suburbios estadounidenses.

Sin embargo, en ningún momento Juan Gelman niega a sus 'otros' como parte de sí mismo, pues no les brinda autonomía e independencia fuera de sí mismo (como hace Fernando Pessoa, por ejemplo). Las 'traducciones' que Gelman realiza son la revelación y exhibición de sus 'otros', pero no son la concesión a que éstos trasciendan más allá de la traducción: "el poeta nos traduce a esos Otros buscando conservar, en- 
tre los giros argentinos, el sedimento cultural y atmosférico de esos seres trashumantes en el tiempo y en el espacio" (Leyva, "Yo poeta", 12).

\section{Otro Juan: el encuentro con la espiritualidad}

Juan Gelman está conformado por los 'otros' a los que crea y reconoce como suyos, pero el poeta también va en búsqueda de algo que lo trascienda, que vaya más allá de ese sentido de extranjería y exilio que le confieren esos 'otros'. Esta búsqueda se plasma en escenas típicas, en retratos de la cotidianeidad, en las expresiones más simples (que al mismo tiempo podrían resultar de mayor complejidad): "Dios (lo que nos trasciende) anda entre los pucheros y las disgresiones, entre los laberintos de la yerba y la plaza pública, entre la fe poética y el idioma, entre el ritual clásico y la herejía” (Monsiváis, "Juan Gelman: ¿Y si Dios dejara de preguntar?", 19).

Para Gelman, el encuentro con lo espiritual y la experiencia mística están íntimamente ligados a la creación poética, pues ambos requieren de fe para conseguir trascender de sí mismo y llegar a otro estado: "hay otra similitud que aproxima a la poesía a la mística: el éxtasis, el salirse de sí” (Leyva y Gelman, "Juan Gelman”, 12). En ese sentido, la poesía también es un camino por el cual el autor opta para salir de sí mismo, para concebirse de nuevo como 'otro'.

Férreo defensor de la vida espiritual de las personas, Gelman no se atiene al marco de una sola religión o culto para buscarse espiritualmente: "lo que percibo, y es a mi juicio solamente, es que desde hace muchos años y desde muchos costados se intenta recortar a la gente la vida espiritual [...]. No estoy hablando de religión, sino simplemente de la vida del espíritu" (Guzón, "La poesía, proveedora de respuestas", 1). Esto es un elemento sumamente interesante de la obra poética de Gelman, pues aunque es judío por herencia familiar, él no se asume miembro practicante de dicha religión y rebate la idea de su pertenencia a ella: "La religión en que realmente creo es la solidaridad humana. Religión en el sentido de su significado original, religare, volver a unir" (Leyva y Gelman, “Juan Gelman”, 1). 
Esta búsqueda espiritual y mística se agudiza con el exilio por el que atravesó a mediados de la década de los setenta. Al verse despojado de sus seres amados, de su tierra natal y de la libertad de expresarse, el autor debe entenderse a sí mismo sin su familia, sin su país y sin su lengua. Se recoge en un proceso que asemejaría al de los místicos (en particular al de san Juan de la Cruz), porque a través de la escritura y lectura, trata de entenderse como un exiliado de todo aquello que ama.

En esta época en particular se avoca al estudio de los místicos españoles san Juan de la Cruz y santa Teresa de Jesús, los místicos judíos Judah Halevi, Yehuda Alharizi, Isaac Luria y Joseph Tsarfati, así como Hildegarde de Bingen y Meister Eckhart. Ese 'otro' Juan (el despojado, el exiliado, el abandonado) recurre a esos Otros por identificación, por equiparación de su búsqueda de Dios con la búsqueda de lo amado: "éxodo, imposibilidad de recuperar lo abandonado, Gelman halla en Los otros la extranjería, la huella de la ausencia, la revelación de su exilio, su desterritorialización, la identidad de ser Otro" (Leyva, "Yo poeta", 10).

Sus experiencias místicas (durante y debido al exilio) son plasmadas en Citas y Comentarios (1982), volumen que reúne poemas escritos en Madrid, París, Zurcí, Ginebra y Calella de la Costa (Comentarios: 1978-1979), así como en Roma (Citas: finales de 1979). Ambos libros se caracterizan por tratar de entender la búsqueda mística propia a través de autores que también estuvieron en ese andar, principalmente san Juan de la Cruz y santa Teresa:

\author{
Cita II (santa teresa) \\ "¿cómo es posible que viviendo \\ esta derrota/tu amistad \\ me cure el alma?/¿cómo \\ me consolás y amás/ abriendomé \\ contra la áspera muerte/y decís \\ palabras herideras como leche \\ para comer como cordero/ \\ poderoso de vos?"
}


Comentario XXIII (san juan de la cruz)

"esta herida con vos/o llaga/luz

como criatura vulnerada $o$

pena de vos que vivemuere

hasta que la matás haciéndola

dicha de vos cielando furias/paladar

al que mi lengua está pegada

como lengua de vos/o tierra donde

crecés como dulzura/vos

que me empezaste y quiero que me acabes

en la mitad de vos/país/amparo

por donde toda la vida va/temblor

que me temblás en vos/claro de fuego"

(Gelman apud Pérez, Oficio Ardiente, 49)

Más tarde escribe Com/posiciones (1986), donde recurre a la exploración de los místicos judíos de lengua hebrea Salomón Ibn Gabirol, Judah Halevi, Yehuda Alharizi, Isaac Luria y Joseph Tsarfati, "con los que Gelman «com/pone» (es decir, pone con) poemas de amor, exilio y supervivencia” (Pérez, "Introducción”, 57). A decir del autor, no pretendía en ningún grado traducir a los autores, mucho menos ofrecer versiones corregidas de sus versos, sino que agregó lo que él mismo pensaba, creía y experimentaba, en coincidencia con el sentimiento de exilio. "Por eso, en el libro, los poemas de amor establecen la ausencia de la amada como el destierro del hombre sobre la tierra, su orfandad cósmica" (Pérez, "Introducción", 58), sentimiento que se acoplaba a la perfección con aquello por lo que Gelman atravesaba: la orfandad de tierra, de identidad, de familia. La aproximación a que llega en Com/ posiciones resulta sumamente interesante, puesto que se acerca a los cabalistas judíos y desde ahí explora al exilio como algo que puede llegar a ser inherente a la cultura judía. Lejos de pretender hacer una valoración universal, lo que Gelman ofrece al lector es una visión personal de lo que él entiende como propio a su cultura e, implícitamente, a su pro- 
pia condición: "una cultura cuya extraordinaria cualidad estriba en que fue construida a lo largo de los siglos alrededor de un vacío: el vacío de Dios, el vacío del suelo original, el vacío que conlleva a la Utopía" (Gelman apud Pérez, 32). Sería precisamente en su siguiente trabajo donde Juan Gelman llega a la maduración en su concepción de la cultura judía y la visión exiliar. La búsqueda quedará explícita y manifiesta en dibaxu, texto publicado en el año de 1994 y en lengua sefardí.

\section{dibaxu}

Conjunto de poemas escritos también en el exilio, dibaxu - "la minúscula como forma infantil o enternecida de la lengua" (Pérez, "Introducción", 12) - fue creado al paso de Gelman por París, Ginebra y París, entre 1983 y 1985 . No obstante, la compilación sería publicada casi 10 años después de concluida, es decir, en 1994.

Dichos poemas fueron escritos en lengua sefardí (también llamada ladino o judío-español), lengua considerada desterrada al igual que sus hablantes: judíos establecidos en la península Ibérica y que fueron expulsados de su tierra en la segunda mitad del siglo Xv. Es precisamente esta combinación de naturaleza exiliar y antigüedad lo que interesa al autor, pues considera que desde el sefardí se pueden rastrear los orígenes de la lengua castellana: "me deslumbró el candor sefardí, el sonar de sus diminutivos, su sintaxis que, efectivamente, obedece a una lógica más antigua, más primitiva entre comillas, con una edificación más significativa cercana al balbuceo" (Leyva y Gelman, "Juan Gelman”, 5).

Es oportuno hacer una acotación en este momento. Juan Gelman es judío por tradición y cultura, pero no por coincidencia religiosa (en algún momento se refirió a sí mismo como cercano al agnosticismo o humanitarismo). Asimismo, su origen no es propiamente sefardí, sino azhkenazí, puesto que su familia proviene de Europa oriental (la antigua URSS). Esta curiosa visión de la religión muy probablemente le venga desde los más tiernos años de su infancia: "en casa no eran religiosos, no obstante que mamá era hija, nieta, biznieta y tataranieta de rabinos. Se celebraban los rituales y fiestas corrientes, por razones más culturales que religiosas" (4). 
La razón de que Gelman utilice el sefardí como lengua base para los poemas de dibaxu, viene explicado por el mismo autor en el "Escolio" (palabra que definía a las anotaciones en los márgenes de un manuscrito):

estos poemas sobre todo son la culminación o más bien el desemboque de Citas y Comentarios, dos libros que compuse en pleno exilio, en 1978 y 1979, y cuyos textos dialogan con el castellano del siglo xvi. Como si buscar el sustrato, hubiera sido mi obsesión. Como si la soledad extrema del exilio me empujara a buscar raíces en la lengua, las más profundas y exiliadas de la lengua (7).

La estructura de dibaxu será la misma en los 29 poemas que conforman la compilación: de temática amorosa, lamentándose por lo perdido y regocijándose de un pasado que una vez fue presente, cada poema está primero escrito en sefardí y luego traducido al español contemporáneo por el mismo autor. Debe considerarse que Gelman no realiza la traducción del español al sefardí, sino del sefardí al español; asimismo, es importante tener en cuenta que esto no lo realiza en vistas de alardear de su conocimiento de la lengua, sino para que el lector pueda acercarse con mayor seguridad "al tiempo que tiembla y que nos da pasado" (7).

Dos ejes temáticos sobresalen de los demás en dibaxu: la importancia del pasado y la orfandad tras el exilio. Respecto al primer eje, Gelman describe al pasado como algo que se encuentra ya muy lejano, pero no por ello deja de estar presente o se desvanece: habita en "la casa del tiempo". 


\section{I}

il batideru di mis bezus/

quero dizer: il batideru di mis bezus

si sintirá in tu pasadu

cun mí in tu vinu/

avrindo la puarta dil tempu/

tu sueniu

dexa cayeryuvia durmida/

dámila tu yuvia/

mi quedarí/ quietu

in tu lluvia di sueniu/

londji nil pinser/

sin spantu/ sin sulvidu/

nila caza dil tiempu

sta il pasadu/

dibaxu di tu piede/

qui baila/

\section{I}

el temblor de mis labios/

quiero decir: el temblor de mis besos

se oirá en tu pasado

conmigo en tu vino/

abriendo la puerta del tiempo/

tu sueño

deja caer lluvia dormida/

dame tu lluvia/

me detendré/ quieto

en tu lluvia de sueño/

lejos en el pensar/

sin temor/ sin olvido/

en la casa del tiempo

está el pasado/

debajo de tu pie/

que baila/

En relación al exilio, se ve que éste toma forma en la ausencia, tanto de lo amado como del amante y, por consecuencia, de lo que no ocurrió entre ellos. La carencia es otra forma de exilio, pues significa que quien no está presente no puede ofrecer algo que daría de estarlo:

\section{$X \boldsymbol{V}$}

tu boz sta escura

di bezus qui a mí no me dieras/

di bezus qui a mí no das/

la nochi es polvu dest'ixiliu/

tus bezus inculgan lunas

qui yelan mi caminu/y

timblu

dibaxu dil sol/

\section{$\boldsymbol{X V}$}

Tu voz está oscura

de besos que no me diste/

de besos que no me das/

la noche es polvo de este exilio/

tus besos cuelgan lunas

que hielan mi camino/ y

tiemblo

debajo del sol/

Un último elemento a considerar en esta obra son las vías por las cuales a Gelman le llega le necesidad de escribir en sefardí. Si bien es cierto que una de las razones de que hubiese acogido esta lengua fue su 
acercamiento a los cabalistas y místicos judíos ocurrido desde la época en que escribió Citas y Comentarios, el autor también expresa que fue gracias a la lectura de Clarisse Nikoïdski que entendió la urgencia de acercarse a las raíces de la lengua española. En ese sentido, es posible decir que el sefardí es aceptado por Gelman vía tradicional y vía contemporánea, pues los poemas de Nikoïdski poseen figuras y metáforas que, al igual que las que Gelman utiliza en dibaxu, difícilmente hubiesen sido halladas "en una lengua que seguramente no las podía concebir” (Sillato, "Dibaxu de Juan Gelman”, 433).

Sin duda alguna, dibaxu es un trabajo trascendental en la carrera de Gelman, mediante el cual expresa la mística de los antiguos judíos sefaradíes y la equipara con lo que él mismo afronta en el exilio. La coincidencia ocurre cuando encuentra que entre ambos fenómenos media la ausencia (para ellos de Dios, para Juan Gelman su país y familia), misma que los trasciende y se convierte así en experiencia mística.

\section{Conclusiones}

Juan Gelman: autor, exiliado, activista, periodista, hombre; en eterna búsqueda, atrapado por el pasado y aprehensor del presente; Sidney West, Yamanokuchi Ando, John Wendell, José Galván, Julio Grecco; judío, agnóstico, humanista. Son tantos los 'Juanes' que caben en él, que no es posible encontrar a uno sólo que sea auténtico y ajeno a los demás.

Sus otros yo (que siempre son Juan), combinan lenguas, locaciones, sentimientos, situaciones, momentos y personas, todo con el propósito de mostrarnos el andar de un hombre extranjero hasta en su propia familia, alejado de quienes ama y exiliado de lo que le es propio: su familia, sus amigos, su Argentina.

Para Juan Gelman la poesía es pasado, pero también es memoria: tener presente lo ocurrido, lo acontecido, lo que ya no puede ser, lo que no se tiene y una vez estuvo ahí. La ausencia y el exilio, entonces son dos formas gelmanianas de expresión, de exploración, de búsqueda.

El misticismo, más que una forma, es una vía en que un Juan (uno de tantos) va en búsqueda de lo ausente... porque la ausencia lo trasciende 
y ahí nace la experiencia mística del autor. La exploración de la lengua sefardí, lejos de ser una acertada coincidencia, es una afortunada veta de exploración gelmaniana. Se remite a sus raíces (sanguíneas, culturales y lingüísticas) a través de la lengua y culmina una larga búsqueda al coincidir con una tradición que, como él, ha soportado los embates de la vida.

\section{REFERENCIAS}

Butazzoni, Fernando, "El poeta Gelman encontró a su nieta desaparecida en Uruguay", El Clarin, $2000<$ http://edant.clarin.com/diario/2000/04/01/ t-01801d.htm $>$ [20/03/2013].

CALvo, Pablo, "Una duda histórica: no se sabe cuántos son los desaparecidos", El Clarin, $2003<$ http://edant.clarin.com/diario/2003/10/06/p-00801.htm> [20/03/2013].

DóminA, Esteban, Historia mínima de Córdoba, Ediciones Boulevard, 2003.

EFE, "Juan Gelman: el dolor no es la fuente de inspiración", El Mundo, 2004 $<$ http://www.elmundo.es/elmundolibro/2004/09/27/poesia/1096299470. $\mathrm{html}>$ [20/03/2013].

Friera, Silvina, "Hay palabras ignoradas que nunca van a asomar", Página $12<\mathrm{http}$ ://www.pagina12.com.ar/diario/suplementos/espectaculos/17-288 27-2013-06-02.html> [2/06/2013].

García González, Sylma, "Yo tuve una cosa con él y no es un concepto", en Originalidad y modernidad en la literatura mística de Ernesto Cardenal, Madrid, Iberoamericana, 2011.

Gelman, Juan, Dibaxu, Buenos Aires, Seix Barral, 1994.

Guzón, Olivia, "La poesía, proveedora de respuestas: Juan Gelman", Locomotor. La Agenda Cultural de Mazatlán, $2013<$ http://www.locomotor.mx/ mazatlan/la-poesia-proveedora-de-respuestas-juan-gelman/> [20/03/2013].

Leibowitz, Yeshayahu, La crisis como esencia de la experiencia religiosa, México, Taurus, 2000.

Leyva, José Ángel, "Yo poeta, el Otro", Los Otros (selección de poemas de Juan Gelman por José Ángel Leyva), México, Universidad Autónoma de Nuevo León, 2008.

LEYvA, José Ángel y Juan Gelman, "Juan Gelman: en la presencia ausente de lo amado", Agulha. Revista cultural, $2008<\mathrm{http}$ ://www.revista.agulha.nom. br/ag66gelman.htm> [12/03/2013].

Monsiváis, Carlos, "Juan Gelman: ¿Y si Dios dejara de preguntar?”, Otromundo: antología, 1956-2007 (selección de poemas de Juan Gelman por Eduardo Hurtado), Madrid, Fondo de Cultura Económica, 2008. 
PÉrez, María Ángeles, "Introducción”, en Oficio Ardiente (selección de poemas de Juan Gelman por María Ángeles Pérez López), Salamanca, Universidad de Salamanca, 2005.

Sillato, María del Carmen, "Dibaxu de Juan Gelman: la poesía desde las exiliadas raíces de la lengua", en Actas XII: Congreso AIM, 1998. Centro Virtual Cervantes [08/03/2013]. 